\title{
Comparison of clotrimazole $1 \%$ cream with $50 \%$ tea tree oil extract in a cream base for the treatment of tinea corporis/cruris: A randomized controlled trial
}

Pokharel $A^{1}$, Yaptinchay $C^{2}$, Thaebtharm $A E^{3}$

${ }^{1}$ Consultant staff, Department of Dermatology, Chitwan Medical College, Bharatpur, Nepal

${ }^{2,3}$ Consultant staff, Department of Dermatology, Jose R Reyes Memorial Medical Center

\begin{abstract}
Background: Tinea cruris and corporis are common diseases and can be widespread. Estimated lifetime probability of contracting the disease is as high as $10-20 \%$. Dermatophytic infections are one of the three most frequently observed skin diseases among poor communities in tropical countries. Tea tree oil exerts its antifungal activity by altering membrane properties and compromising membrane associated function resulting in clinical improvement and mycological cure of superficial dermatophytes.

Objectives: The aim of this study is to determine the efficacy and safety of tea tree oil $50 \%$ in a cream base compared with clotrimazole $1 \%$ cream for the treatment of tinea corporis or cruris.

Material and Methods: Sixty patients were enrolled in the study and randomized into tea tree oil and clotrimazole groups with 30 patients in each group. Both groups were instructed to apply cream two times a day after cleaning with soap for 4 weeks. The patients were asked to follow-up every 2 weeks for photography, microscopic and clinical assessment. Before enrollment, patient signed a written consent form.
\end{abstract}

Results: Using intention to treat analysis, the assessment of mycological cure, clinical cure, global physician assessments and overall patient perception were done. There were no statistical difference of all the parameters between tea tree oil group and clotrimazole group.

Conclusion: Tea tree oil $50 \%$ cream is safe and as effective as clotrimazole $1 \%$ cream for the treatment of tinea corporis or cruris.

Keywords: Tinea corporis, Tea tree oil, Dermatitis

Address for correspondence

Dr. Achyut Pokharel

Department of Dermatology,

Chitwan Medical College, BNP-10, Bharatpur, Nepal

Email:pachyut@gmail.com

Phone: +977-9851188898 


\section{Original Article}

\section{Introduction}

Tinea corporis is a superficial cutaneous fungal infection clinically characterized by annular plaques, usually sharply marginated with raised borders and mild scales. Single lesions or multiple annular patches to plaques may occur. ${ }^{1}$ Tinea cruris and tinea corporis are common and widespread. Estimated lifetime probability of contracting the disease is as high as $10-20 \%{ }^{2}$ Dermatophytic infections are one of the three most frequently observed skin diseases among poor communities in tropical countries. ${ }^{3}$ It is commonly caused by Trichophyton rubrum, $T$. mentagrophytes and Epidermophyton floccosum. Treatment of tinea corporis varies according to the areas involved. For localized infection, topical therapy is recommended. Topical azoles and allylamines show high rates of clinical efficacy. These agents inhibit synthesis of ergosterol, which is a major fungal cell membrane sterol. Systemic therapy may be indicated for tinea corporis that includes extensive skin infection, immunosuppression, resistance to topical antifungal therapy, and co- morbidities of tinea capitis or tinea unguium.

Tea tree oil is an essential oil extracted primarily from the leaves of Melaleuca alternifolia, an Australian native. It has been used as a germicidal agent since the early twentieth century for a wide variety of ailments such as wound infections, bacterial and fungal infections of the skin, and oral mucosa. During World War I, tea tree oil was included in the first-aid kits of Australian troops to treat burns, bites, and infections. Clinical studies have suggested tea tree oil to be effective in treating tinea pedis, ${ }^{4}$ onychomycosis, ${ }^{5}$ trichomonal vaginitis, ${ }^{6}$ acne, ${ }^{7}$ and dandruff. ${ }^{8}$ Tea tree oil is a complex mixture of hydrocarbons and terpenes, consisting of almost 100 substances, and the antimicrobial activity appears to be related to the major component, terpinen-4-ol, 12 which accounts for one-third of the final volume of tea tree oil. The minimum inhibitory concentration of tea tree oil for T. rubrum is $1.0 \%$ volume/volume and T. mentagrophytes $0.3-0.4 \%$ volume/ volume. ${ }^{4}$
Studies revealed that the lower concentration of tea tree oil cream also shows a greater clinical improvement but not mycological cure. ${ }^{9}$ Therefore, it was considered that an increased concentration of tea tree oil might be more effective in achieving mycological cure. ${ }^{9}$ Tea tree oil and components appear to affect membrane properties and integrity in a manner consistent with other lipophilic, membrane-active agents such as the terpenes thymol and geraniol. The different components of tea tree oil vary in their modes of action against yeasts and that tea tree oil has several mechanisms of antifungal action. ${ }^{10}$

\section{Methodology Study design}

A prospective, randomized, double-blind, controlled clinical trial was conducted over a 4month period. Among 250 day patients seen in hospital Out Patient Department (OPD) in department of Dermatology, sixty patients with tinea corporis or cruris who signed the consent form and fall in the inclusion criteria were enrolled in the study over three months period. The even number 60 was chosen to divide them in two equal groups. Informed consent as secured from the patients prior to the start of treatment and ethical clearance taken.

\section{Subjects \\ Inclusion criteria}

1. Male or female subjects between 17 to 65 years with localized tinea corporis or cruris confirmed by direct microscopy and willing to sign a written consent form.

2. Patients without any prior treatment of the lesions for at least two weeks before the study enrollment period.

\section{Exclusion criteria}

1. Patient with associated dermatophytosis involving other body areas such as the palm, soles, scalp and nails.

2. Patient with extensive lesions with large areas of trunk, groin and limbs involved and are not suitable for topical treatment. 


\section{Original Article}

3. Patient with previous history or known allergy to Tea tree oil and its vehicle components

4. Patient who received topical antifungal within 2 weeks prior to study or systemic drugs such as corticosteroids, antibiotics, immunosuppressive, and antifungal agents within the previous 4 weeks

5. Patients with secondary bacterial infections 6. Pregnant women and lactating mothers.

\section{Intervention}

Sixty patients were divided into 2 groups: treatment with tee tree oil $50 \%$ cream and clotrimazole $1 \%$ cream. Randomization was performed using computer generated random numbers. All dispensed cream tubes were identical in appearance, color and texture but identified by either letter A containing tee tree oil $50 \%$ cream or B containing $1 \%$ clotrimazole cream. The $50 \%$ tea tree oil was prepared by a registered pharmacist in a lab and $1 \%$ clotrimazole cream was bought in a generic pharmacy. Neither the investigators nor the patients were aware of the treatment to which the patients were assigned until the study was completed.

They were instructed to wash the affected areas with soap and water then pat dried. Next they were advised to apply the cream to affected areas two times a day for 4 weeks. The selection of a four week treatment period was based on standard therapy for tinea pedis with most currently available topical antifungals. ${ }^{4}$ The patients were advised not to use any other antifungal agents.

The patients were reviewed at 2 weeks and 4 weeks. At each visit, photographs were taken and clinical assessment was made for erythema and scaling by the investigator (Dermatology resident) and pruritus by the patient. Each of these was graded as absent, mild, moderate, severe and very severe and given a corresponding score of 0 to 4. The scores were added together to give a clinical score. A marked clinical response was considered to be a reduction of 2 or less than 2 . The mycological cure rate was determined from $\mathrm{KOH}$ of skin scrapings taken at baseline and on each follow-up. Effective cure was considered to be both a marked clinical response and negative $\mathrm{KOH}$. Each patient was asked to assess the pruritus on each follow up. This was graded absent, mild, moderate, and severe and given a corresponding score of 0 to 3. Each patient was also asked to assess on overall satisfaction which was graded from greatly improved, somewhat improved, the same, somewhat worse and much worse with a score each from 5 to 1 .

Global physician assessment was done at the end of the four weeks on each patient graded as clear, excellent, good, fair, poor, unchanged, and worse. Improvement between 90 and 100\% were categorized as excellent and considered clinical cure and below $90 \%$ were categorized from good to worse and were considered not cured. Data collection was done from three investigators who were Residents of Dermatology. The collected data's were sent to a registered statistician for the data analysis. Results of clinical improvement scores, patient perception and global physician response were statistically evaluated using student t-test. Results of $\mathrm{KOH}$ test was statistically evaluated using pearson chi square test.

\section{Result:}

A baseline demographic comparison of the 2 groups of patients (tea tree oil and clotrimazole) is shown in Table 1.

Table 1: Baseline demographic data

\begin{tabular}{|l|c|c|c|c|}
\hline $\begin{array}{l}\text { Demographic } \\
\text { data. }\end{array}$ & $\begin{array}{c}\text { Tea tree oil } \\
\text { group - 30 } \\
\text { Mean } \\
\text { (standard } \\
\text { deviation) }\end{array}$ & $\begin{array}{c}\text { Clotrimazole } \\
\text { group - 30) } \\
\text { Mean } \\
\text { (Standard } \\
\text { deviation) }\end{array}$ & $\begin{array}{c}\text { Total } \\
\text { Mean } \\
\text { (Standard } \\
\text { deviation) }\end{array}$ & P- value \\
\hline $\begin{array}{l}\text { Age } \\
\text { Mean age }\end{array}$ & $30.27(2.34)$ & $35.1(14.49)$ & 32.68 & $\begin{array}{c}\text { (Student's } \\
\text { t-test) } 0.1766\end{array}$ \\
\hline $\begin{array}{l}\text { Sex } \\
\text { Females } \\
\text { Males }\end{array}$ & $12(40 \%)$ & $13(43.33 \%)$ & $25(41 \%)$ & (Pearson ch \\
test) 0.793 \\
$\begin{array}{l}\text { Duration of } \\
\text { Infection } \\
\text { (weeks) }\end{array}$ & $17(56.67 \%)$ & $35(59 \%)$ & \\
$\begin{array}{l}\text { Mean } \\
\text { Range }\end{array}$ & $1-12$ & $1-12$ & $1-12$ & \\
\hline $\begin{array}{l}\text { Site } \\
\text { Body } \\
\text { Groin }\end{array}$ & 14 & 11 & 25 & \\
\hline
\end{tabular}




\section{Original Article}

The patients of both groups were not statistically different in regards to age $(\mathrm{p}=0.1766)$ and sex $(\mathrm{p}=0.793)$.

For mycological cure, there were not enough evidence for significant statistical difference in proportion between the two groups at week $2(p=0.176)$ and week $4(p=0.774)$ (Table 2) (Figure 1).

Table 2: Mycological cure at week 2 and week 4

\begin{tabular}{|c|c|c|c|}
\hline Study group & $\begin{array}{c}\text { Baseline } \\
\text { (Positive } \\
\text { microscopy) }\end{array}$ & $\begin{array}{c}2 \text { weeks } \\
\text { (Negative } \\
\text { microscopy) } \\
\left(\text { Pearson } \text { ch }^{2} \text { test }\right) \\
(\mathrm{p}=0.795)\end{array}$ & $\begin{array}{c}4 \text { weeks } \\
\text { (Negative } \\
\text { microscopy) } \\
\left(\text { Pearson } \text { ch }^{2} \text { test }\right) \\
(\mathrm{p}=0.05)\end{array}$ \\
\hline Tea tree oil & 30 & $18(60 \%)$ & $21(70 \%)$ \\
\hline Clotrimazole & 30 & $17(56.62 \%)$ & $27(90.0 \%)$ \\
\hline
\end{tabular}

For clinical cure, the number of patients with a marked improvement between tea tree oil group and clotrimazole group were not significantly different with mean score of 2.97 of tea tree oil and 3.27 of clotrimazole group with $p=0.4361$ at week 2 and with mean score of 2.0 of tea tree oil and 2.03 of clotrimazole group with $\mathrm{p}=0.9455$ at week 4 (Table 3 ).

Table 3: Clinical response and cure

\begin{tabular}{|c|c|c|c|c|}
\hline $\begin{array}{c}\text { Study } \\
\text { Group }\end{array}$ & Cure & $\begin{array}{c}\text { Baseline } \\
\text { Mean score } \\
\text { (Standard } \\
\text { deviation) } \\
(\mathrm{p}=0.6429)\end{array}$ & $\begin{array}{c}\text { Week 2 } \\
\text { Mean score } \\
\text { (Standard } \\
\text { deviation) } \\
(\mathrm{p}=0.4361)\end{array}$ & $\begin{array}{c}\text { Week 4 } \\
\text { Mean score } \\
\text { (Standard } \\
\text { deviation) } \\
(\mathrm{p}=0.9455)\end{array}$ \\
\hline Tea tree oil & $25 / 30$ & $4.77(1.59)$ & $2.97(1.54)$ & $2.0(1.72)$ \\
\hline Clotrimazole & $24 / 30$ & $4.93(1.14)$ & $2.27(1.39)$ & $2.03(2.03)$ \\
\hline
\end{tabular}

The clinical pictures of pre and post treatment by tea tree oil cream is shown in Figure 2, and by clotrimazole 1\% cream is shown in Figure 3.

For global physician response, three investigators were involved with cleared/excellent values for tea tree oil for investigator 1, 2 and 3 were 14, 13 and 15 , similarly for clotrimazole 14,13 and 14 respectively. Using Cohen's kappa coefficient, the $\mathrm{K}=0.9121$ with $\mathrm{p}<0.001$. This means that there is very good agreement among the ratings of investigator 1 , investigator 2 and investigator 3 (Table 4).

Table 4: Global Physician Response (Agreement)

\begin{tabular}{|l|c|c|c|c|}
\hline Study Group & $\begin{array}{c}\text { Investigator } \\
1\end{array}$ & $\begin{array}{c}\text { Investigator } \\
2\end{array}$ & $\begin{array}{c}\text { Investigator } \\
3\end{array}$ & $\begin{array}{c}\text { Cohen's } \\
\text { kappa and } \\
\mathrm{p} \text {-value }\end{array}$ \\
\hline Tea tree oil & 14 & 13 & 15 & $\mathrm{~K}=0.9121$ \\
\hline Clotrimazole & 14 & 13 & 14 & $\mathrm{p}<0.001$ \\
\hline
\end{tabular}

For patient perception on overall satisfaction, there was no statistical differences between the two groups with mean score of 3.70 for tea tree oil and 3.7 for clotrimazole with $\mathrm{p}=0.4204$ at week 2 and 4.03 for tea tree oil and 4.07 for clotrimazole with $\mathrm{p}=0.8305$ at week 4 (Table 5).

Table 5: Patient Perception for overall improvement

\begin{tabular}{|l|c|c|}
\hline Study & $\begin{array}{c}\text { Week 2 } \\
\text { Mean (Standard deviation) } \\
(\mathrm{p}=0.4204)\end{array}$ & $\begin{array}{c}\text { Week 4 } \\
\text { Mean (Standard deviation) } \\
(\mathrm{p}=0.8305)\end{array}$ \\
\hline Tea tree oil & $3.79(0.41)$ & $4.03(0.57)$ \\
\hline Clotrimazole & $3.7(0.47)$ & $4.07(0.58)$ \\
\hline
\end{tabular}

The patients were also assessed by the improvement of mean pruritus score from baseline and compared to the mean scores at week 2 and week 4 between two groups. Using student T test, there were no evidence of statistical difference in the change in their mean pruritus score at baseline $(\mathrm{p}=0.7948)$, week $2(\mathrm{p}=0.8630)$ and week $4(\mathrm{p}=0.99)$ between two groups. There were $11(18.33 \%)$ patients lost to follow-up, but the results were based on the intention to treat analysis.

On second week of follow up, one patient from tea tree oil group developed multiple erythematous papules with some coalescing to form plaques on an erythematous base on the areas where tea tree oil 50\% cream was applied and was considered as allergic contact dermatitis which was confirmed by a patch test. The patient was withdrawn from the study and the lesion resolved on stopping the cream and topical steroid (Betamethasone valerate cream). There were no serious adverse events reported. 


\section{Original Article}

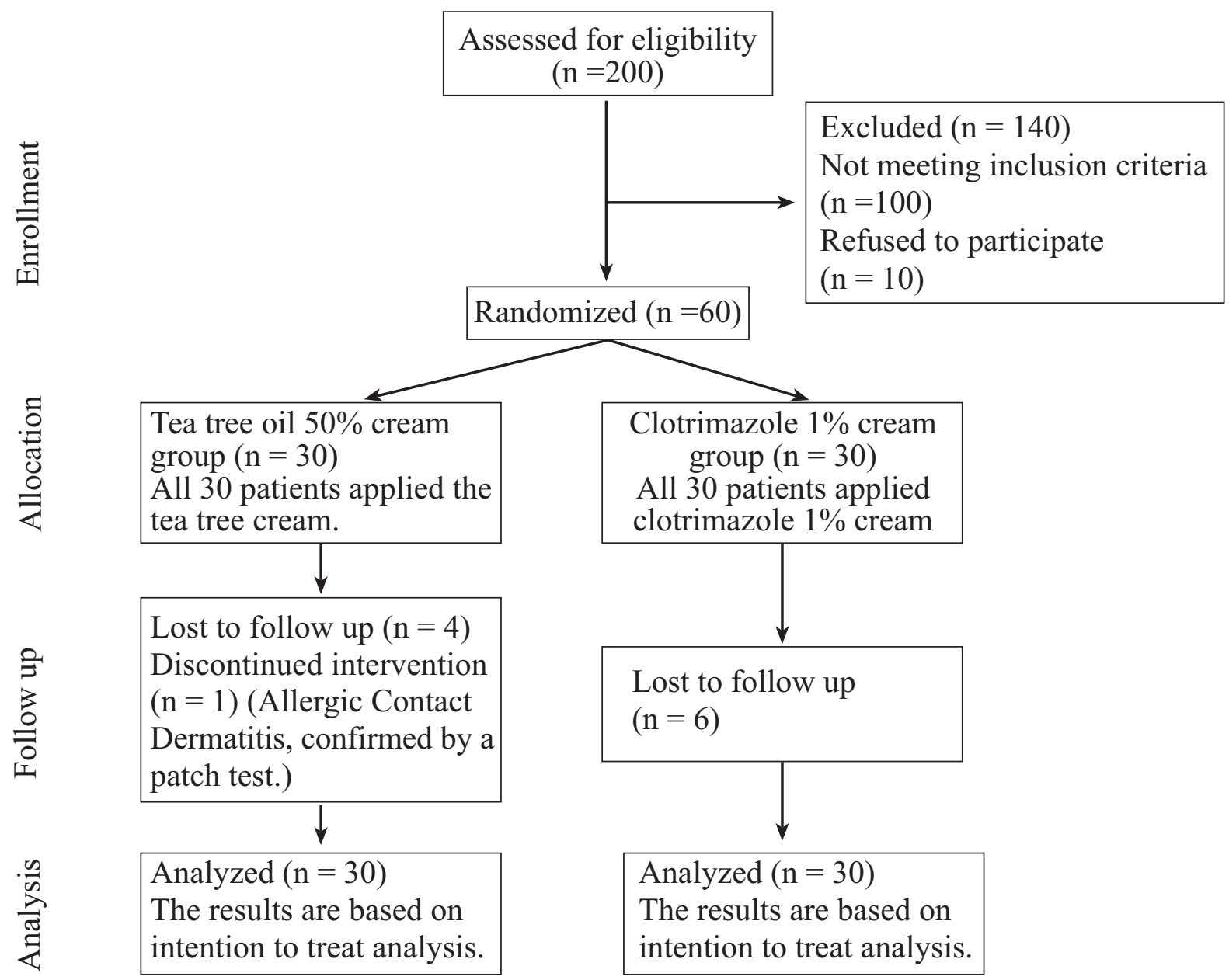

Figure 1: Consort diagram showing the flow of participants through each stage of the randomized trial.
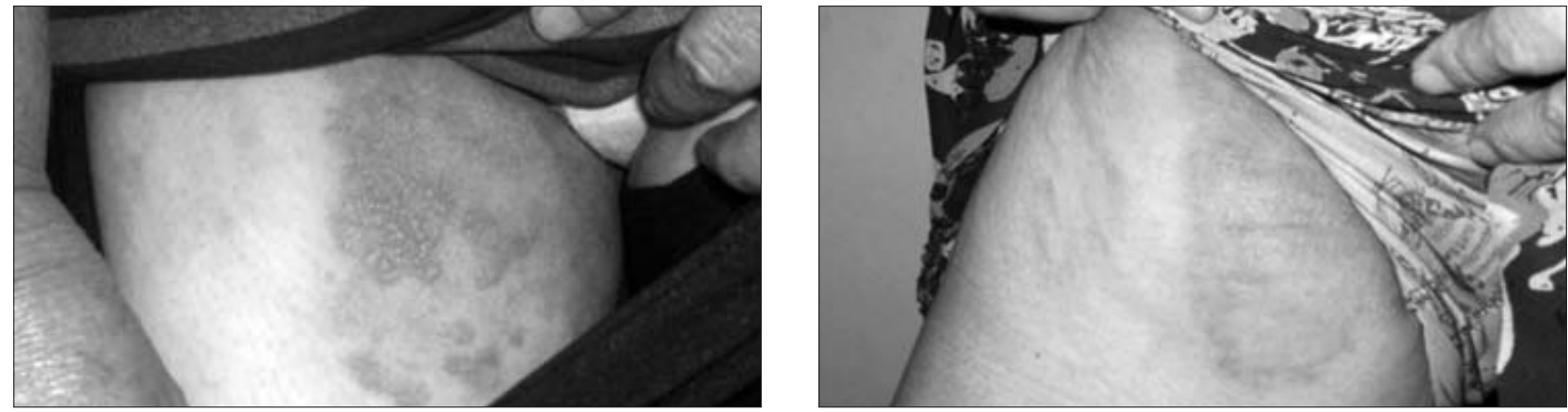

Figure 2: Pre and post treatment with tea tree oil
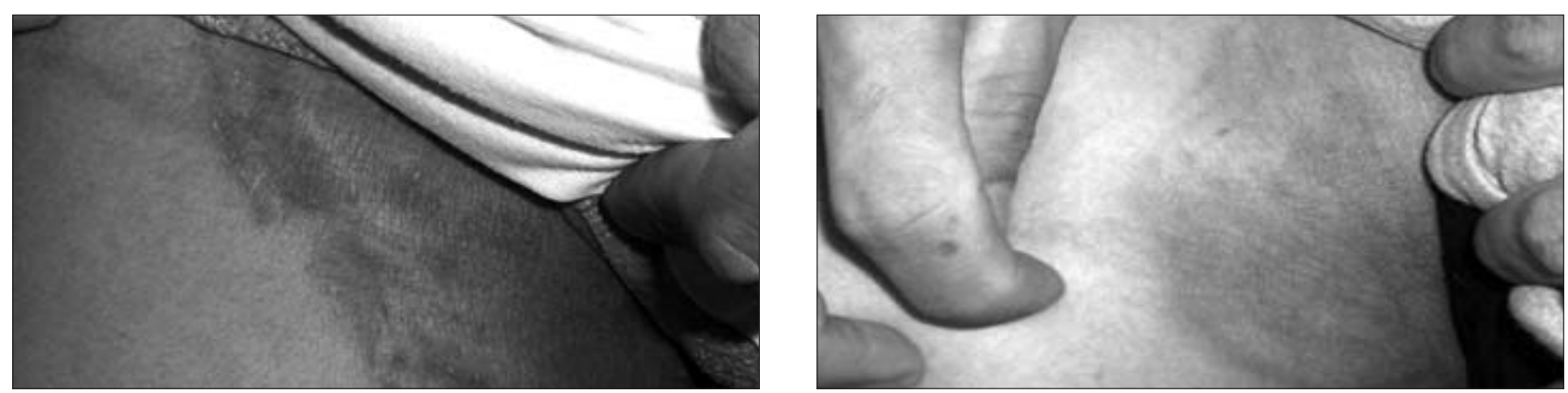

Figure 3: Pre and post treatment with clotrimazole 1\% cream 


\section{Original Article}

\section{Discussion}

In recent years there has been an increasing demand for natural medicinal products, especially Australian tea tree oil (Melaleuca alternifolia). This essential oil contains about 100 different compounds comprising mainly plant terpenes and their corresponding alcohols, which have been separated and quantified by gas chromatography. Tea tea oil possesses in vitro activity against a wide range of microorganisms (minimal concentration to inhibit $90 \%$ organisms; MIC90) such as Propionibacterium acnes $(0.75 \% \mathrm{v} / \mathrm{v})$, Staphylococcus aureus $(0.63 \% \mathrm{v} / \mathrm{v})$, Escherichia coli $(0.63 \% \mathrm{v} / \mathrm{v})$, Candida albicans $(0.63 \% \mathrm{v} / \mathrm{v})$, Aspergillus flavus $(0.25 \% \mathrm{v} / \mathrm{v})$, Trichophyton mentagrophytes $(0.75 \% \mathrm{v} / \mathrm{v})$, and Trichophyton rubrum $(0.5 \% \mathrm{v} / \mathrm{v}){ }^{2}$ There are clinical studies comparing different concentrations of tea tree oil with activity against dermatophytes. ${ }^{9}$ This study compared a commonly used antifungal (clotrimazole 1\% cream) and tea tree oil $50 \%$ in a cream base for the activity against dermatophytes. The results were similar between the two groups.

Tea tree oil is known to interact with certain plastic types and has been shown to both deform and migrate through polymers such as low-density polyethylene which significantly lower the MIC and MFC for activity against dermatophytes. ${ }^{11}$ Tea tree oil $50 \%$ cream for our study was packaged in aluminum tubes.

Allergy to tea tree oil preparations is relatively common in patch-test population and is often relevant to the presenting dermatitis. ${ }^{12}$ Despite its popularity in causing allergic contact dermatitis, its use in already irritated or broken skin is high.

In a study of patch testing of 25 normal volunteers, 3 people developed allergic contact dermatitis. ${ }^{9}$ In our study, out of 30 patients one patient developed allergic contact dermatitis which resolved on stopping the medication. The purpose of fungal culture in any suspected dermatophyte infection is to identify the causative organism. Its goal is to determine whether the isolated fungus is clinically significant to validate the efficacy of the drug being tested. ${ }^{13}$

Many pathogenic fungi such as dermatophytes grow slowly hence the possibility of overgrowth by rapidly growing contaminants decreases the probability of isolating the causative agent. In this study, we did not perform fungal culture. Clinical diagnosis and mycological confirmation was done by microscopy.

\section{Conclusion}

Tea tree oil $50 \%$ cream appeared to be as effective as clotrimazole $1 \%$ cream in reducing signs and symptoms and for mycological cure of tinea cruris or corporis. Inter-subject variability in terms of personal hygiene and compliance may have contributed to this result. We recommend that $50 \%$ tea tree oil in a cream base be considered in those patients keen to use herbal agents in the treatment of tinea corporis or cruris.

\section{References}

1. Gorani A, Sciera A, Oriani A. Widespread tinea corporis tinea corporis due to Trichophyton rubrum. Mycoses 2002; 45: 195-97. http://dx.doi.org/10.1046/j.1439-0507.2002.00759.x

2. Shannon V, Michael PH. Superficial Fungal infection: Dermatophytosis, Onychomycosis, Tinea nigra, Piedra. In: Fitzpatrick's Dermatology in General Medicine, Clauss W, Lowell AG. $7^{\text {th }}$ ed. New York; 2008: p1807-21.

3. Hay R, Sandra EB, Suephy C. Skin Diseases. In: Dean TJ, Joel GB, Anthony RM, George A, Marium C, David EB, Prabhat J, editors. Disease Control Priorities in developing countries. $2^{\text {nd }}$ ed. New York: The World Bank and Oxford University Press; 2006: p707-21.

4. Tong MM, Altman PM, Barnetson RStC. Tea tree oil in the treatment of tinea pedis. Australas J Dermatol. 1992; 33: 145-9. http://dx.doi.org/10.1111/j.1440-0960.1992.tb00103.x 


\section{Original Article}

5. Buck DS, Nidorf DM, Addino JG. Comparison of two topical preparations for the treatment of onychomycosis: Melaleuca alternifolia (tea tree) oil and clotrimazole. J Fam Prac 1994; 38: $601-5$.

6. Pena EF. Melaleuca alternifolia oil, uses for trichomonal vaginitis and other vaginal infections. Obstet Gynaecol 1962; 19: 793-5.

7. Bassett IB, Pannowitz DL, Barnetson RSC. A comparative study of tea-tree oil versus benzoylperoxide in the treatment of acne. Med J Aust 1990; 153: 455-8.

8. Satchell AC, Saurajen A, Bell C, Barnetson RSC. Treatment of dandruff with 5\% tea tree oil shampoo. J Am Acad Dermatol 2002; 47: 152-5. http://dx.doi.org/10.1067/mjd.2002.122734

9. Andrew CS, Anne S, Craig B, Ross SC, Barnetson. Treatment of interdigital tinea pedis with $25 \%$ and $50 \%$ tea tree oil solution: A randomized, placebo controlled, blinded study. Australasian Journal of Dermatology 2002; 43: 175-8. http://dx.doi.org/10.1046/j.1440-0960.2002.00590.x

10. Hammer KA, Carson CF, Riley TV. Atifungal effects of Melaleuca alternifolia (tea tree) oil and its components on Candida albicans, Candida glabrata and Saccharomyces cerevisiae. Journal of Antimicrobial Chemotherapy 2004; 53: 1081-5. http://dx.doi.org/10.1093/jac/dkh243

11. Hammer KA, Carson CF, Riley TV. Antifungal activity of the components of Melaleuca alternifolia (tea tree) oil. Journal of Applied Microbiology 2003; 95: 853-60. http://dx.doi.org/10.1046/j.1365-2672.2003.02059.x

12. Tim R, Rosemary N, Mei T, Bruce T. Allergy to tea tree oil: Retrospective review of 41 cases with positive patch tests over 4.5years. Australasian Journal of Dermatology 2007; 48: 83-7. http://dx.doi.org/10.1111/j.1440-0960.2007.00341.x

13. Forbes BA, Betty A. "Laboratory methods in basic Mycology." In: Forbes BA, Sahm DF, Weissfeld AS, editors. Bailey \& Scott's Diagnostic Microbiology. $10^{\text {th }}$ ed. St. Louis: Mosby; 1998: p68-192. 